
A $\mathbf{C}_{\mathrm{ASE}} \mathbf{S}_{\mathrm{TUdy}}$
FOOD SCIENCE
RESEARCH JOURNAL
e ISSN-2230-9403 $\boldsymbol{\square}$ Visit us : www.researchjournal.co.in
Volume 6 | Issue 2 | October, 2015 | 404-408
DOI : $10.15740 / \mathrm{HAS} / \mathrm{FSRJ} / 6.2 / 404-408$

\title{
Influence of environmental factors, parental attributes and feeding practices on prevalence of severely acute malnutrition among children
}

\author{
ChandRashree LenKa
}

\begin{abstract}
Environment plays an important role in the growth and development of children. The objectives of the present research was to study the environmental factors, parental attributes and feeding practices of the children suffering from Severely Acute Malnutrition (SAM). One hundred children suffering from Severely Acute Malnutrition attending NRHM centre of Malkanagiri District, Odisha were selected by random purposive sampling method for the present study. Pretested questionnaires and required tools were used to collect information. The results of the study revealed that majority of the respondents were belonged to the age group of 7 months to 2 years. Most of the parents were labourers having annual income less than Rs.30,000 and were illiterate. Maximum families (63\%) had more than four children. Age at marriage was found to be less than 15 years in case of 74 per cent mothers and had their first child at the age of 16 years in 60 per cent respondents. Joint family system heaving more than 3 children was found to be prevalent in that area. Birth spacing was found to be 10 month or less than 1 year in 33 per cent cases. Exclusive breast feeding was practised among 61 per cent respondents and rest of the respondents took only Mandia Peja along with Breast Milk upto one year of age. 56 per cent children continues to take breast milk upto three years of age. One year onwards most of the children were fed with home prepared diet along with Anganwadi supplied food. "Salafa" one type of beverage was also taken by the children. Thus it can be concluded that poor environmental factors and faulty feeding practices were the main contributory causes for prevalence of Severely Acute Malnutrition among the respondents.
\end{abstract}

Key Words : Food habits, Severely acute malnutrition, Breast feeding

How to cite this article : Lenka, Chandrashree (2015). Influence of environmental factors, parental attributes and feeding practices on prevalence of severely acute malnutrition among children. Food Sci. Res. J., 6(2): 404-408. 